\title{
Biomarkers of hemodynamic stress and aortic stiffness post-STEMI: a cross-sectional analysis
}

\author{
Sebastian J Reinstadler ${ }^{1 *}$, Hans-Josef Feistritzer ${ }^{1}$, Gert Klug ${ }^{1}$, Luc Huybrechts', Angelika Hammerer-Lercher², \\ Johannes M Mair ${ }^{1}$, Wolfgang-Michael Franz ${ }^{1}$, Bernhard Metzler ${ }^{1}$ \\ From 18th Annual SCMR Scientific Sessions \\ Nice, France. 4-7 February 2015
}

\section{Background}

We aimed to evaluate the association between biomarkers of hemodynamic stress and aortic stiffness assessed at a chronic stage after ST-segment elevation myocardial infarction (STEMI).

\section{Methods}

Fifty-four patients four months after acute STEMI were enrolled in this cross-sectional, single-center study. Nterminal pro B-type natriuretic peptide (NT-proBNP), mid-regional pro-A-type natriuretic peptide (MR-proANP) and mid-regional pro-adrenomedullin (MR-proADM) levels were measured by established assays. Aortic stiffness was assessed by the measurement of pulse wave velocity using velocity-encoding, phase-contrast cardiovascular magnetic resonance imaging.

\section{Results}

NT-proBNP, MR-proANP and MR-proADM concentrations were all correlated with aortic stiffness in univariate analysis $(\mathrm{r}=0.378, \mathrm{r}=0.425, \mathrm{r}=0.532$, all $\mathrm{p}<0.005$, respectively). In multiple linear regression analysis, NT-proBNP $(\beta=0.316, \mathrm{p}=0.005)$ and MR-proADM $(\beta=$ $0.284, p<0.020)$ levels were associated with increased aortic stiffness independently of age, blood pressure and renal function. In receiver operating characteristic analysis, NT-proBNP was the strongest predictor for high aortic stiffness (area under the curve: 0.82, 95\% CI 0.67 - 0.96).

\section{Conclusions}

At a chronic stage after STEMI, concentrations of biomarkers for hemodynamic stress, especially NT-proBNP, are positively correlated with aortic stiffness. These biomarkers

'University Clinic of Internal Medicine III, Cardiology and Angiology, Medical University Innsbruck, Innsbruck, Austria

Full list of author information is available at the end of the article might also be useful as predictors of high aortic stiffness post-STEMI.

\section{Funding}

Austrian Society of Cardiology.

\section{Authors' details}

'University Clinic of Internal Medicine III, Cardiology and Angiology, Medical University Innsbruck, Innsbruck, Austria. ${ }^{2}$ Central Institute for Medical Laboratory Diagnostics, Medical University of Innsbruck, Innsbruck, Austria.

Published: 3 February 2015

\section{doi:10.1186/1532-429X-17-S1-P146}

Cite this article as: Reinstadler et al: Biomarkers of hemodynamic stress and aortic stiffness post-STEMI: a cross-sectional analysis. Journal of Cardiovascular Magnetic Resonance 2015 17(Suppl 1):P146.
Submit your next manuscript to BioMed Central and take full advantage of:

- Convenient online submission

- Thorough peer review

- No space constraints or color figure charges

- Immediate publication on acceptance

- Inclusion in PubMed, CAS, Scopus and Google Scholar

- Research which is freely available for redistribution
() Biomed Central 